\title{
Self-Disclosure, Interpersonal Relationships, and Stickiness of Online Communities
}

\author{
Ying-Wei Shih ${ }^{1}$, Meng-Hsu Hsu ${ }^{2}$, De-Chih Lee ${ }^{3}$ \\ ${ }^{1}$ Department of Information Management, National Changhua University of Education, Changhua, Taiwan \\ ${ }^{2}$ Graduate Institute of Technology Management, National Chung Hsing University, Taichung City, Taiwan \\ ${ }^{3}$ Department of Information Management, Da-Yeh University, Dacun, Changhua, Taiwan
}

\section{Email address:}

ywshih@im.ncue.edu.tw (Ying-Wei Shih), tonyy1990@gmail.com (Meng-Hsu Hsu), dclee@mail.dyu.edu.tw (De-Chih Lee)

\section{To cite this article:}

Ying-Wei Shih, Meng-Hsu Hsu, De-Chih Lee. Self-Disclosure, Interpersonal Relationships, and Stickiness of Online Communities. Psychology and Behavioral Sciences. Vol. 4, No. 2, 2015, pp. 71-78. doi: 10.11648/j.pbs.20150402.16

\begin{abstract}
Online communities change the way people interact. Due to the high diversity of online communities, how to maintain and increase user participation is an important issue for the administrators of those sites. This study first examines propensity to trust, need for affiliation, and exhibitionism as antecedents to self-disclosure and relationship maintenance and further explores the effects of self-disclosure and relationship maintenance on intimacy as well as the relation of intimacy to stickiness. By convenience and snowball sampling, 503 valid responses to an online questionnaire were collected. Data was analyzed using SPSS 20.0 and AMOS 7.0. Results indicate that need for affiliation and exhibitionism have positive effects on self-disclosure, that propensity to trust and need for affiliation are antecedents to relationship maintenance, that self-disclosure and relationship maintenance contribute to intimacy, and that intimacy reinforces stickiness to online communities.
\end{abstract}

Keywords: Propensity to Trust, Need for Affiliation, Exhibitionism, Self-Disclosure, Relationship Maintenance, Intimacy, Stickiness

\section{Introduction}

Browsing the Internet has become a regular activity of daily living for many people. Among the various types of Web sites, online communities are novel Web sites which enable users to interact with one another and to establish and maintain interpersonal relationships in a virtual environment. The prevalence of mobile devices and wireless Internet has allowed people to share information without being constrained by temporal or spatial boundaries. Consequently, people become heavily reliant on online communities, and tend to spend an extensive amount of time using such platforms [1].

According to the Market Intelligence and Consulting Institute [2], as of May 21, 2013, approximately 17.98 million people in Taiwan use the Internet regularly, which is approximately $79 \%$ of the national population. Specifically, Web portals were the most frequently visited, followed by online communities. Generally, one-third of people in Taiwan are frequent users of online communities. The Market Intelligence and Consulting Institute [3] also reported that $84.6 \%$ of students in Taiwan use online communities to contact real-life friends, and $82.8 \%$ of people most frequently use online communities to contact friends and relatives.

Stickiness is a crucial factor that influences Web site sustainability [4]. Because the switching cost is low, users can easily shift between online communities [5]. Thus, understanding how the stickiness of online community users can be increased is a critical research topic. Accordingly, this study was conducted to investigate how such factors as personal traits, self-disclosure, relationship maintenance behavior, and intimacy influence user stickiness. The examined personal traits were propensity to trust, need for affiliation, and exhibitionism.

\section{Principal Constructs}

McKnight and Chervany [6] defined propensity to trust as a human psychological trait and an inherent quality that generates trust in other people under any situations. Online community users with high trust propensity experience no difficulty communicating and interacting with other members [7], which has a positive influence on their ability to develop interpersonal relationships [8].

McClelland [9] considered affiliation as a need to engage 
in friendly and intimate relationships. Jha [10] argued that establishing interpersonal relationships is a basic human need. Generally, people who have great needs for affiliation tend to spend more time than others on participating in communities and maintaining their social relations. Casciaro [11] assumed that the need for affiliation increases a person's attention to their informal friendship networks, prompting him or her to engage in building and maintaining harmonious relationships.

In the context of online communities, narcissistic personality traits manifest as frequently posting recent activities, updating statuses, and other forms of self-disclosure [12]. Rose and Campbell [13] indicated that people having a quality of exhibitionism tend to demonstrate their superiority over others. Moreover, Ryan and Xenos [14] showed that exhibitionistic Facebook users update their activities more frequently than other users.

In the virtual environment, people can present their ideal self through selective self-disclosure, thereby engaging in further communications [15]. Park et al. [16] argued that self-disclosure can be investigated through quantity and quality aspects, where quantity and quality respectively represent the breadth and depth of disclosed information.
Interpersonal relationships develop through socialization processes. Bippus and Rollin [17] indicated that relationship maintenance facilitates pro-social behavior. Online communities are platforms where people interact with one another to build new, maintain existing [18], and strengthen weakened interpersonal relationships [19].

The level of intimacy represents the strength of an online interpersonal relationship. Rau et al. [20] indicated that online communities not only function as a communication channel, but they also facilitate establishing trustworthy and intimate social relationships. In computer-mediated communication, intimacy mitigates the uncertainty people experience when interacting with others [21, 22].

\section{Research Model and Hypotheses}

Figure 1 depicts the research model. This study investigated how personal traits (i.e., propensity to trust, need for affiliation, and exhibitionism) influence the development of interpersonal relationships (i.e., self-disclosure, relationship maintenance, and intimacy). Subsequently, it examined the effect of intimacy on stickiness.

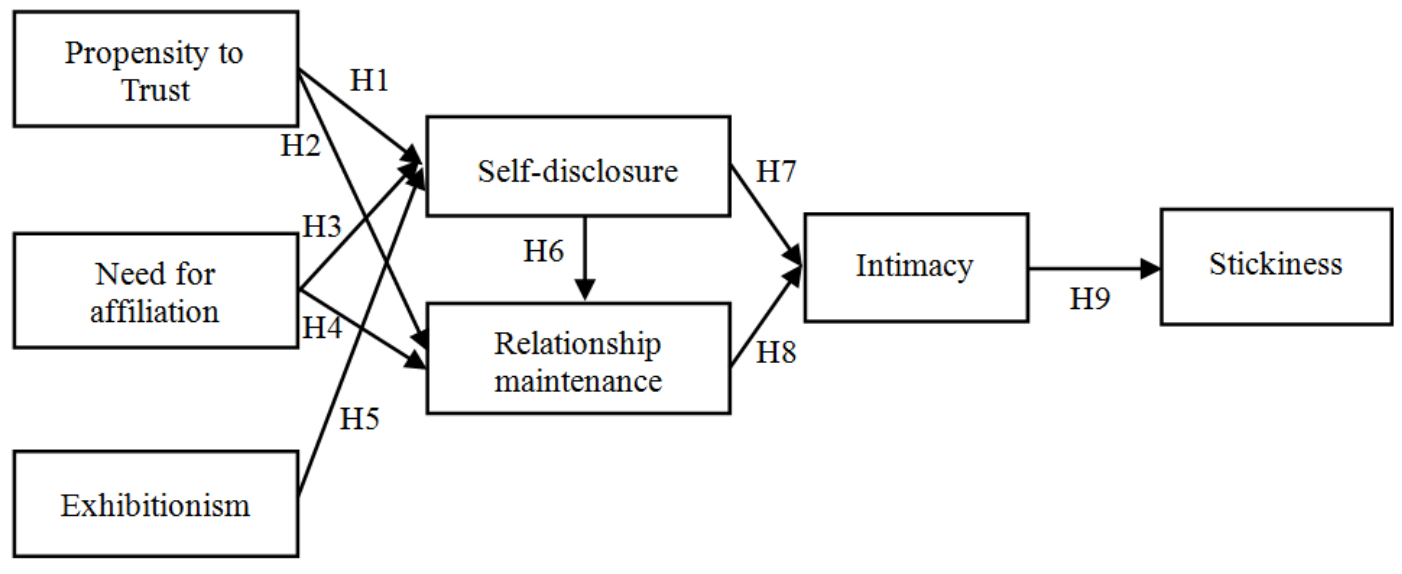

Figure 1. Research model.

\subsection{Propensity to Trust}

Gefen [23] argued that consumer propensity to trust affects their trust in e-commerce. Propensity to trust also affects the manner in which people share knowledge. Ridings et al. [24] reported that propensity to trust can be used to predict whether people in the virtual environment engage in interaction and information acquisition. Since propensity to trust is a factor influencing people's willingness to trust others, online community users with higher propensity to trust are more inclined to exhibit self-disclosure behaviors. Accordingly, we proposed the following hypothesis:

H1: Propensity to trust exerts a positive effect on self-disclosure.

Propensity to trust affects the development of interpersonal relationships. Hsu et al. [25] indicated that from a psychological perspective, trust can be regarded as a motive that stimulates people to maintain relationships. According to
Hwang [26], correctly applying communication vehicles to relationship maintenance can produce a satisfactory result. On the basis of trust, people are generally more willing to share their experiences and feelings [27]. Therefore, we asserted that online community users with high propensity to trust are willing to interact and communicate with other users to maintain their relationships. Accordingly, we proposed the following hypothesis:

H2: Propensity to trust exerts a positive effect on relationship maintenance.

\subsection{Need for Affiliation}

Peter and Valkenburg [28] indicated that in the online environment, a great need for affiliation is related to a person's behaviors of intimate communication and self-disclosure. People with great needs for affiliation tend to exhibit a broad scope of authentic self-disclosure behaviors [16]. Technological advancements allow people with strong 
needs for affiliation to contact and communicate with other people on online communities and to maintain their relationships through self-disclosure. Therefore, we proposed the following hypothesis:

H3: Need for affiliation has a positive effect on self-disclosure.

Tsai et al. [29] confirmed that needs for affiliation have a positive impact on member interaction in brand communities. Regarding the factors motivating people to use Facebook, Park et al. [16] found that Facebook users' needs for affiliation have positive influence on their relationship maintenance behaviors. In the present study, we considered online communities to be communication channels through which users who have strong needs for affiliation are more willing to establish and maintain relationships with other users. Accordingly, we proposed the following hypothesis:

H4: Need for affiliation has a positive effect on relationship maintenance.

\subsection{Exhibitionism}

Hollenbaugh [30] identified exhibitionism as an underlying factor motivating blog authors to maintain their blogs, implying that they want to enhance their reputation by sharing stories about their life experiences. Hollenbaugh and Ferris [31] targeted Facebook users and confirmed that exhibitionism significantly influenced the amount of self-disclosure. Therefore, we proposed the following hypothesis:

H5: Exhibitionism has a positive effect on self-disclosure.

\subsection{Self-Disclosure}

Valkenburg and Peter [32] argued that the Internet stimulates people to increase intimate self-disclosure, thereby facilitating forming and maintaining relationships. Online communities provide means for users to build and maintain meaningful relationships, which can be reinforced by the users' self-disclosure behaviors. Thus, self-disclosure behavior is a pivotal element for successful relationship maintenance in an online community [33]. Accordingly, we proposed the following hypothesis:

H6: Self-disclosure has a positive effect on relationship maintenance.

Bazarova \& Choi [34] argued that disclosure for relational development promotes intimacy and closeness with others. Bauminger et al. [35] investigated how self-disclosure influences intimacy in adolescent friendships and identified the direct influence of self-disclosure on intimacy. Park et al. [16] also indicated that in online communities, the amount of self-disclosure affects the level of intimacy among site members. Therefore, we proposed the following hypothesis:

H7: Self-disclosure has a positive effect on intimacy.

\subsection{Relationship Maintenance}

By using communication tools, people can expand their social networks and strengthen their intimate relationships [36]. Ledbetter [37] studied relationship maintenance behaviors and found that such behaviors are associated with friendship closeness. Therefore, we proposed the following hypothesis:

H8: Relationship maintenance has a positive effect on intimacy.

\subsection{Intimacy}

Lee and Kwon [38] found that affective factors influence whether people continue to use online services. In online communities, users who develop a high level of intimacy with others frequently engage in online activities [39, 40, 41]. Based on this position, we considered that affective factors increase the frequency at which people use the Internet. Hence, we hypothesized that online community users who develop a high level of intimacy have a high level of stickiness toward their preferred online communities. Therefore, we proposed the following hypothesis:

H9: Intimacy has a positive effect on stickiness.

\section{Methodology}

A questionnaire survey was conducted to collect data. The questionnaire comprised two parts: six items for acquiring demographic information and 34 items for measuring research constructs. The measurement items of research constructs were adapted from previous studies and were evaluated using a seven-point Likert-type scale with values ranging from 7 (strongly agree) to 1 (strongly disagree) (see Table 1).

Table 1. Measurement items of research constructs.

\begin{tabular}{ll}
\hline Propensity to trust [23] & \\
TRU1 & Generally, participants in online communities are reliable. \\
TRU2 & I tend to rely on participants in online communities. \\
TRU3 & Generally, I have trust in humanity. \\
TRU4 & I will trust participants in online communities unless given a good reason not to. \\
Need for affiliation [16] & \\
NEE1 & I spend a lot of time having talks (or chatting) with others. \\
NEE2 & I am an easy-going person. \\
NEE3 & I like to work with others. \\
NEE4 & I prefer learning and working with a group of people. \\
\hline
\end{tabular}




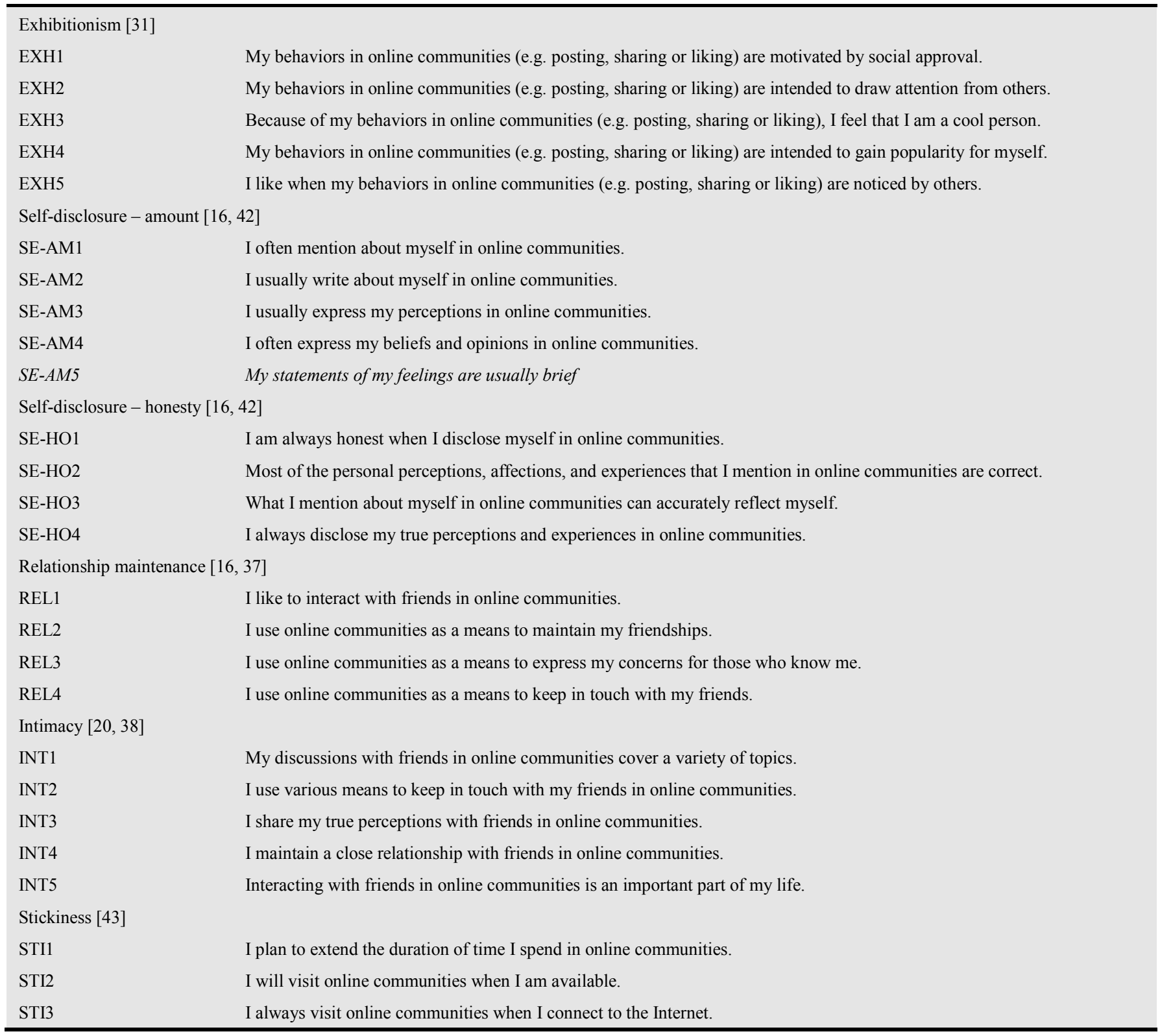

In the pretest of questionnaire, two professors, one in the field of information management and the other one in the field of applied mathematics, and two graduate students majoring in information management evaluated all items. Based on their assessments, we removed one item (SE-AM5) that was considered confusing. To prevent common method bias, the questionnaire items were arranged in a random order for the subsequent pilot test.

In the pilot test, 100 questionnaires were distributed among a researcher's friends and relatives. Subsequently, we analyzed the reliability and validity of the items by conducting item analysis, confirmatory factor analysis (CFA), and reliability analysis. The item analysis showed that the item-to-total correlations of the items ranged from 0.350 to 0.755 , which are all higher than the recommended value of $0.3[44,45]$. The CFA revealed that three items (i.e., NEE1, INT3, and STI1) had standardized factor loadings below the threshold value of 0.5 [46], and therefore were removed from the final questionnaire. Regarding the reliability analysis, all the constructs had values of Cronbach's $\alpha$ and composite reliability larger than the recommended value of 0.7 [46], indicating that all constructs achieved satisfactory reliability.

We used an online questionnaire design service, mySurvey (www.mysurvey.tw), to construct the official questionnaire. Research participants were users of online communities, who were selected by performing convenience sampling and snowball sampling. We invited such users to complete the survey by posting a link to the questionnaire on various social media, including Facebook, Google+, Plurk, and Twitter. We also asked those users to assist with distributing the questionnaire to members of their social circles. To encourage users to respond to the questionnaire, we implemented a lottery system and awarded prizes to 10 respondents. Each winner received a NT\$100 coupon that could be used at 7-Eleven convenience stores. The questionnaire survey was conducted from February 27 to 
March 13, 2014. Among the 527 responses obtained, only 14 were invalid, yielding a total of 503 valid responses (valid response rate $=99.2 \%$ ). Table 2 shows the demographic information of the respondents.

Table 2. Sample profile.

\begin{tabular}{|c|c|c|c|}
\hline & & n & $\%$ \\
\hline \multirow{2}{*}{ Gender } & Male & 295 & 58.6 \\
\hline & Female & 208 & 41.4 \\
\hline \multirow{5}{*}{ Age } & $<20$ & 231 & 45.9 \\
\hline & $21-30$ & 237 & 47.1 \\
\hline & $31-40$ & 20 & 4.0 \\
\hline & $41-50$ & 12 & 2.4 \\
\hline & $>50$ & 3 & 0.6 \\
\hline \multirow{4}{*}{ Education } & Junior high & 2 & 0.4 \\
\hline & Senior high & 201 & 40.0 \\
\hline & Undergraduate & 192 & 38.2 \\
\hline & Graduate & 108 & 21.5 \\
\hline \multirow{4}{*}{ Experience of participating in online communities } & $<1$ year & 9 & 1.8 \\
\hline & $1-3$ years & 178 & 35.4 \\
\hline & $4-5$ years & 215 & 42.7 \\
\hline & $>5$ years & 101 & 20.1 \\
\hline \multirow{5}{*}{ Frequency of use online communities } & once a week (or less) & 21 & 4.2 \\
\hline & 2-3 times a week & 42 & 8.3 \\
\hline & 2-3 times a week & 31 & 6.2 \\
\hline & once a day & 107 & 21.3 \\
\hline & Several times a day & 302 & 60.0 \\
\hline \multirow{6}{*}{ Number of friends in online communities } & $<100$ & 68 & 13.5 \\
\hline & $101-200$ & 141 & 28.0 \\
\hline & $201-300$ & 106 & 21.1 \\
\hline & $301-400$ & 55 & 10.9 \\
\hline & $401-500$ & 40 & 8.0 \\
\hline & $>500$ & 93 & 18.5 \\
\hline
\end{tabular}

\section{Results}

The reliability analysis demonstrated that the values of Cronbach's $\alpha$ and composite reliability for each construct ranged from 0.728 to 0.894 and from 0.734 to 0.925 , respectively, indicating that the reliability of the official questionnaire was acceptable.

CFA was used to test the convergent validity. The results show that the standardized factor loadings of the items ranged from 0.559 to 0.871 , and the squared multiple correlation coefficient of each item was higher than 0.2 , indicating acceptable convergent validity. The discriminant validity was tested using a bootstrap confidence interval method. We used Amos Version 7.0 and set the confidence intervals to be $95 \%$ and bootstrapping to be 200 . The bootstrap confidence interval method compares the confidence intervals of the correlations between the research constructs. If the confidence intervals do not include 1 , the null hypothesis will be rejected, signifying that the constructs possess acceptable discriminant validity [47]. In this study, the confidence intervals we obtained by using the bias-corrected method and the percentile method did not include 1, implying favorable discriminant validity among the constructs.

We confirmed the goodness-of-fit of the data to the model before performing the structural model analysis. The results in Table 3 indicate that the goodness-of-fit indices were acceptable.

Table 3. Goodness-of-fit indices.

\begin{tabular}{llll}
\hline Indices & $\begin{array}{l}\text { Recommended } \\
\text { values }\end{array}$ & Sources & Values \\
\hline$\chi^{2}$ & & & 1373.77 \\
df & & Bollen [48] & 392 \\
$\chi^{2} / \mathrm{df}$ & $<=5$ & Seyal et al. [49] & 3.51 \\
GFI & $>=0.8$ & Segars and Grover [50] & 0.83 \\
AGFI & $>=0.8$ & Mulaik et al. [51] & 0.80 \\
PGFI & $>=0.5$ & Browne and Cudeck [52] & 0.70 \\
RMSEA & $<=0.08$ & & 0.07 \\
\hline
\end{tabular}

For the structural model analysis, we used Amos Version 7.0 to calculate the $R^{2}$ for each dependent variable. Figure 2 shows that the $R^{2}$ of self-disclosure, relationship maintenance, intimacy, and stickiness were $.762, .667, .934$, and .558, respectively. Propensity to trust significantly influenced relationship maintenance $(\beta=.396, t=4.269, p<.001)$, but its effect on self-disclosure was insignificant $(t=1.472)$. Need for affiliation significantly affected both self-disclosure $(\beta=.458, t=5.559, p<.001)$ and relationship maintenance $(\beta=0.330, t=3.932, p<.001)$, and exhibitionism significantly affected self-disclosure $(\beta=.385, t=5.031, p$ $<.001)$. Self-disclosure exerted a significant effect on intimacy $(\beta=.342, t=5.614, p<.001)$, but no effect on relationship maintenance $(t=1.630)$. Finally, intimacy was 
significantly affected by relationship maintenance $(\beta=.689, t$ $=9.525, p<.001)$, and stickiness was significantly influenced by intimacy $(\beta=.747, t=11.755, p<.001)$.

\section{Discussions and Conclusions}

This study investigated whether propensity to trust, need for affiliation, and exhibitionism affect self-disclosure. The significant effect of need for affiliation on self-disclosure differs from results reported by Park et al. [16]. Furthermore, the significant effect of exhibitionism on self-disclosure supports the result obtained by Hollenbaugh and Ferris [31], implicating that exhibitionistic people have a higher tendency to exhibit self-disclosing behaviors. However, the insignificant effect of propensity to trust on self-disclosure could be explained by the anonymity associated with the Internet and by limited access to viewing others' private statuses in online communities. Therefore, individuals' propensity to trust does not influence their self-disclosure behaviors.

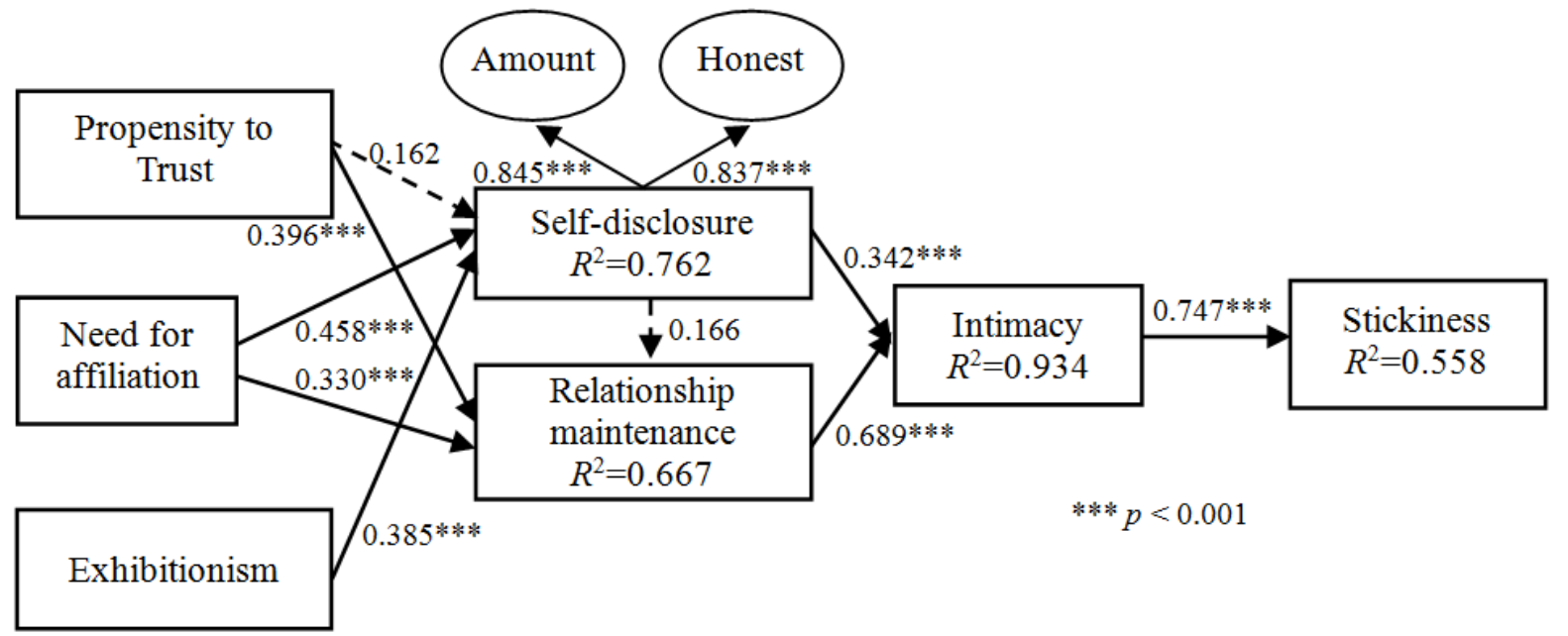

Figure 2. Result of path analysis.

The significant effects of propensity to trust and need for affiliation on relationship maintenance indicate that interpersonal relationships must be based on trust, and that users who desire to interact with other people may use online communities to maintain their interpersonal relationships [25].

The insignificant effect of self-disclosure on relationship maintenance may have occurred because people might engage in self-disclosure for reasons other than maintaining interpersonal relationships. In addition, the significant effects of self-disclosure and relationship maintenance on intimacy confirm the findings obtained by Bauminger et al. [35] and Ledbetter [37]. In online communities, when users disclose more personal information and constantly interact with other participants, the intimacy among them increases, which further causes users to use online communities more frequently.

Regarding the practical implications of these findings, online community administrators and operators should consider the following suggestions: (a) provide incentives for users to engage in self-disclosure; (b) continually improve the authentication function of their services; and (c) develop new modules that provide functionalities to assist users with managing their contacts.

The present study examined propensity to trust, need for affiliation, and exhibitionism as antecedents of self-disclosure. Future studies should consider investigating other factors that affect self-disclosure, as well as the behaviors and emotions that might be influenced by self-disclosure.

Regarding the limitations encountered while conducting this study, only users of such social media as Facebook, Google+, Plurk, and Twitter were investigated. Given the wide variety of online communities, future studies should consider investigating users of commercial (e.g., LinkedIn) and thematic (e.g., PTT) online communities. Finally, we adopted convenience and snowball sampling strategies to collect the data; consequently, most survey participants were younger than 30 years of age. Therefore, the influence of age should be considered when interpreting the results of this study.

\section{References}

[1] DigiTimes (2014). Embracing social commerce. URL: http://www.bnext.com.tw/article/view/id/30634, retrieved at March, 2014.

[2] Market Intelligence and Consulting Institute (2013). Analyses of user activities in online communities using PC and mobile devices. URL: http://mic.iii.org.tw/aisp/reports/reportdetail.asp?docid=CDO C20130724012\&doctype $=$ RC\&smode $=1$, retrieved at March $18,2014$.

[3] Market Intelligence and Consulting Institute (2014). Analyses of use of online communities (II). URL: http://mic.iii.org.tw/aisp/reports/reportdetail.asp?docid=CDO C20140505002\&doctype $=\mathrm{RC}$, retrieved at June 3, 2014. 
[4] Yeh, R. C., Lin, Y.-C., Tseng, K.-H., Chung, P., Lou, S.-J., \& Chen, Y.-C. (2013). Why do people stick to play social network sites?: An extension of expectation-confirmation model with perceived interpersonal values and playfulness perspectives. Studies in Computational Intelligence, 457, 37-46.

[5] Zhou, T., Li, H., \& Liu, Y. (2010). The effect of flow experience on mobile SNS users' loyalty. Industrial Management \& Data Systems, 110(6), 930-946.

[6] McKnight, D. H., \& Chervany, N. L. (2001). What trust means in e-commerce customer relationships: An interdisciplinary conceptual typology. International Journal of Electronic Commerce, 6(2), 35-59.

[7] Sun, T., \& Wu, G. (2011). Traits, predictors, and consequences of Facebook self-presentation. Social Science Computer Review, 30(4), 419-433.

[8] Casaló, L. V., Flavián, C., \& Guinalíu, M. (2008). Fundaments of trust management in the development of virtual communities. Management Research News, 31(5), 324-338.

[9] McClelland, D. C. (1961). The Achieving Society. Princeton, NJ: Van Nostrand.

[10] Jha, S. (2010). Need for growth, achievement, power and affiliation: Determinants of psychological empowerment. Global Business Review, 11(3), 379-393.

[11] Casciaro, T. (1998). Seeing things clearly: Social structure, personality, and accuracy in social network perception. Social Networks, 20(4), 331-351.

[12] Panek, E. T., Nardis, Y., \& Konrath, S. (2013). Mirror or megaphone?: How relationships between narcissism and social networking site use differ on Facebook and Twitter. Computers in Human Behavior, 29(5), 2004-2012.

[13] Rose, P., \& Campbell, W. K. (2004). Greatness feels good: A telic model of narcissism and subjective well-being. In S. P. Shohov (Ed), Advances in Psychology Research, Vol. 31 (pp. 3-26). Hauppauge, NY: Nova Science Publishers.

[14] Ryan, T., \& Xenos, S. (2011). Who uses Facebook?: An investigation into the relationship between the Big Five, shyness, narcissism, loneliness, and Facebook usage. Computers in Human Behavior, 27(5), 1658-1664.

[15] Nguyen, M., Bin, Y. S., \& Campbell, A. (2012). Comparing online and offline self-disclosure: A systematic review. Cyberpsychology, Behavior, and Social Networking, 15(2), 103-111.

[16] Park, N., Jin, B., \& Jin, S.-A. A. (2011). Effects of self-disclosure on relational intimacy in Facebook. Computers in Human Behavior, 27(5), 1974-1983.

[17] Bippus, A. M., \& Rollin, E. (2003). Attachment style differences in relational maintenance and conflict behaviors: Friends' perceptions. Communication Reports, 16(2), 113-123.

[18] Thelwall, M., \& Wilkinson, D. (2010). Public dialogs in social network sites: What is their purpose? Journal of the American Society for Information Science and Technology, 61(2), 392-404.

[19] Ellison, N. B., Vitak, J., Gray, R., \& Lampe, C. (2014). Cultivating social resources on social network sites: Facebook relationship maintenance behaviors and their role in social capital processes. Journal of Computer-Mediated
Communication, 19(4), 855-870.

[20] Rau, P.-L. P., Gao, Q., \& Ding, Y. (2008). Relationship between the level of intimacy and lurking in online social network services. Computers in Human Behavior, 24(6), 2757-2770.

[21] Cooper, A., \& Sportolari, L. (1997). Romance in cyberspace: Understanding online attraction. Journal of Sex Education \& Therapy, 22(1), 7-14.

[22] Morey, J. N., Gentzler, A. L., Creasy, B., Oberhauser, A. M., \& Westerman, D. (2013). Young adults' use of communication technology within their romantic relationships and associations with attachment style. Computers in Human Behavior, 29(4), 1771-1778.

[23] Gefen, D. (2000). E-commerce: The role of familiarity and trust. Omega, 28(6), 725-737.

[24] Ridings, C. M., Gefen, D., \& Arinze, B. (2002). Some antecedents and effects of trust in virtual communities. The Journal of Strategic Information Systems, 11(3-4), 271-295.

[25] Hsu, C.-L., Liu, C.-C., \& Lee, Y.-D. (2010). Effect of commitment and trust towards micro-blogs on consumer behavioral intention: A relationship marketing perspective. International Journal of Electronic Business Management, 8(4), 292-303.

[26] Hwang, Y. (2011). Is communication competence still good for interpersonal media?: Mobile phone and instant messenger. Computers in Human Behavior, 27(2), 924-934.

[27] Taddei, S., \& Contena, B. (2013). Privacy, trust and control: Which relationships with online self-disclosure? Computers in Human Behavior, 29(3), 821-826.

[28] Peter, J., \& Valkenburg, P. M. (2006). Research note: Individual differences in perceptions of Internet communication. European Journal of Communication, 21(2), 213-226.

[29] Tsai, H.-T., Huang, H.-C., \& Chiu, Y.-L. (2012). Brand community participation in Taiwan: Examining the roles of individual-, group-, and relationship-level antecedents. Journal of Business Research, 65(5), 676-684.

[30] Hollenbaugh, E. E. (2010). Personal journal bloggers: Profiles of disclosiveness. Computers in Human Behavior, 26(6), $1657-1666$.

[31] Hollenbaugh, E. E., \& Ferris, A. L. (2014). Facebook self-disclosure: Examining the role of traits, social cohesion, and motives. Computers in Human Behavior, 30, 50-58.

[32] Valkenburg, P. M., \& Peter, J. (2007). Preadolescents' and adolescents' online communication and their closeness to friends. Developmental Psychology, 43(2), 267-277.

[33] Vitak, J. (2012). The impact of context collapse and privacy on social network site disclosures. Journal of Broadcasting \& Electronic Media, 56(4), 451-470.

[34] Bazarova, N. N., \& Choi, Y. H. (2014). Self-disclosure in social media: Extending the functional approach to disclosure motivations and characteristics on social network sites. Journal of Communication, 64(4), 635-657.

[35] Bauminger, N., Finzi-Dottan, R., Chason, S., \& Har-Even, D. (2008). Intimacy in adolescent friendship: The roles of attachment, coherence, and self-disclosure. Journal of Social and Personal Relationships, 25(3), 409-428. 
[36] Wolak, J., Mitchell, K. J., \& Finkelhor, D. (2002). Close online relationships in a national sample of adolescents. Adolescence, 37(147), 441-455.

[37] Ledbetter, A. M. (2009). Family communication patterns and relational maintenance behavior: Direct and mediated associations with friendship closeness. Human Communication Research, 35(1), 130-147.

[38] Lee, Y., \& Kwon, O. (2011). Intimacy, familiarity and continuance intention: An extended expectation-confirmation model in web-based services. Electronic Commerce Research and Applications, 10(3), 342-357.

[39] Haythornthwaite, C. (2002). Strong, weak, and latent ties and the impact of new media. The Information Society: An International Journal, 18(5), 385-401.

[40] Hsu, C.-W., Wang, C.-C., \& Tai, Y.-T. (2011). The closer the relationship, the more the interaction on Facebook? Investigating the case of Taiwan users. Cyberpsychology, Behavior, and Social Networking, 14 (7-8), 473-476.

[41] Mesch, G. S., \& Talmud, I. (2006). Online friendship formation, communication channels, and social closeness. International Journal of Internet Science, 1(1), 29-44.

[42] Wheeless, L. R. (1978). A follow-up study of the relationships among trust, disclosure, and interpersonal solidarity. Human Communication Research, 4(2), 143-157.

[43] Lin, J. C.-C. (2007). Online stickiness: Its antecedents and effect on purchasing intention. Behaviour \& Information Technology, 26(6), 507-516.

[44] Yang, K.-Y., \& Heh, J.-S. (2007). The impact of Internet virtual physics laboratory instruction on the achievement in physics, science process skills and computer attitudes of 10th-grade students. Journal of Science Education and Technology, 16(5), 451-461.

[45] Yusoff, M. S. B. (2011). Psychometric properties of the learning approach inventory: A confirmatory factor analysis. Education in Medicine Journal, 3(2), e24-e31.

[46] Hair, J. F., Anderson, R. E., Tatham, R. L., \& Black, W. C. (1998). Multivariate Data Analysis (5th edition), Englewood Cliffs, NJ: Prentice Hall.

[47] Torkzadeh, G., Koufteros, X., \& Pflughoeft, K. (2003). Confirmatory analysis of computer self-efficacy. Structural Equation Modeling: A Multidisciplinary Journal, 10(2), 263-275.

[48] Bollen, K. A. (1989). Structural Equations with Latent Variables. New York: Wiley.

[49] Seyal, A. H., Rahman, M. N. A., \& Rahim, M. M. (2002). Determinants of academic use of the Internet: A structural equation model. Behaviour \& Information Technology, 21(1), 71-86.

[50] Segars, A. H., \& Grover, V. (1993). Re-examining perceived ease of use and usefulness: A confirmatory factor analysis. MIS Quarterly, 17(4), 517-525.

[51] Mulaik, S. A., James, L. R., Van Alstine, J., Bennett, N., Lind, S., \& Stilwell, C. D. (1989). Evaluation of goodness-of-fit indices for structural equation models. Psychological Bulletin, 105(3), 430-445.

[52] Browne, M. W., \& Cudeck, R. (1992). Alternative ways of assessing model fit. Sociological Methods \& Research, 21(2), 230-258. 